\title{
Low Birth Weight in Neonates of Iran 2015
}

\author{
Hossein Kazemeini ${ }^{1}$, Hamid Reza Lornezhad ${ }^{2}$, Ahad Banar ${ }^{3}$ \\ ${ }^{1}$ PHC Center, Ministry of Health and Medical Education, Tehran, Iran \\ ${ }^{2}$ Family Health Office, Ministry of Health and Medical Education, Tehran, Iran \\ ${ }^{3}$ Office of Strategic Planning and Control, Ministry of Health and Medical Education, Tehran, Iran \\ Email: kazemeini2002@yahoo.com, *lornejad@health.gov.ir, ahadbanar@gmail.com
}

How to cite this paper: Kazemeini, H., Lornezhad, H.R. and Banar, A. (2017) Low Birth Weight in Neonates of Iran 2015. Open Journal of Preventive Medicine, 7 , 202-209.

https://doi.org/10.4236/ojpm.2017.710016

Received: September 1, 2017

Accepted: October 20, 2017

Published: October 23, 2017

Copyright $\odot 2017$ by authors and Scientific Research Publishing Inc. This work is licensed under the Creative Commons Attribution International License (CC BY 4.0).

http://creativecommons.org/licenses/by/4.0/

\begin{abstract}
Background: Low birth weight has been defined by the World Health Organization (WHO) as weight at birth of less than 2500 grams. Any baby born prematurely is more likely to be small. However there are other factors that can also contribute to the risk of low birth weight, these include: race, mothers' age, multiple births, mothers' health and mothers of lower socioeconomic status. The incidence of low birth weight is monitored through both health system surveillance and household surveys. Among regions, South Asia has the highest incidence of low birth weight, with one in four newborns weighing less than 2500 grams. In a study in Iran the prevalence of LBW was estimated 7 percent (SD 95\%), prevalence of LBW is different according to the geographical region. Methods: Demographic data got from mothers and children height and weight measured by trained staffs in and out of hospital and health facilities. Results: Total number of births in Iran in 2015 is 1,509,081 that from this 777,351 are male, 731,014 are female and 716 ambiguous. The percentage of LBW in male, female and ambiguous is 6.5, 7.7 and 53.9 respectively. The highest percent of LBW in female was related to Sistan Blochestan province with 12.6 and the lowest percent to Lorestan province with 5.6 percent. Discussion: According to the guidelines published by World Health Organization (WHO), any neonate with a birth weight less than 2500 grams is considered to be LBW. LBW and PTM are leading causes of adverse perinatal outcomes and are closely related to neonatal diseases and deaths. In the world, there are more than 20 million LBW infants born each year that $95.6 \%$ are born in developing countries. In the present study, the number of LBW neonate in male, female and ambiguous was 50,569, 55,972 and 386; the percentage of LBW in male, female and ambiguous was 6.5, 7.7 and 53.9 respectively. Regarding the prognosis of LBW, with development of perinatology, the survival rate of LBW infants has substantially increased. However, some adverse outcomes are still relatively common, especially long-term complications such as cerebral palsy, delayed neurodevelopment and visual and hearing impair-
\end{abstract}


ments. Conclusions: The incidence of LBW in Iran is higher in deprived provinces such as Sistan Blochestan in southeast of Iran.

\section{Keywords}

LBW, Iran, 2015

\section{Introduction}

Low birth weight has been defined by the World Health Organization (WHO) as weight at birth of less than 2500 grams (5.5 pounds) [1]. This practical cut-off for international comparison is based on epidemiological observations that infants weighing less than $2500 \mathrm{~g}$ are approximately 20 times more likely to die than heavier babies [2].

Any baby born prematurely is more likely to be small. However there are other factors that can also contribute to the risk of low birth weight, these include: race, mothers' age, multiple births, mothers' health and mothers of lower socioeconomic status [3].

Intrauterine growth and development are one of the most vulnerable processes in the human life cycle and the aberrations can result in profound and lasting influence in later life [4].

LBW infants encompass a heterogeneous population of newborns. Broadly, the birth weights may be low because the baby is born small for gestational age (SGA), as a result of intrauterine growth retardation (synonym intrauterine malnutrition) (IUGR) or because birth is preterm. The immediate sequlae of low birth weight is respiratory failure, hypoxia, intraventricular hemorrhage. Consequences of low birth weight continue in adulthood causing a range of chronic diseases like ischaemic heart disease, stroke, hypertension, diabetes, metabolic syndrome, malignancies, dementia and osteoarthritis [1]. In the developed countries, the overwhelming majority of LBW infants are preterms, whereas in the developing nations, the reverse is the case. The great majority of newborns with LBW are full term infants who are SGA [5].

WHO and UNICEF published the first global, regional and country estimates of low birth weight rates in 1992 [4]. At that time, the low birth weight rate for developed countries was around 7 percent and in less developed countries it ranged between 5 and 33 percent, with an average of 17 percent [6].

The incidence of low birth weight is monitored through both health system surveillance and household surveys.

In 2013, nearly 22 million newborns-an estimated 16 percent of all babies born globally that year-had low birth weight. Accurate monitoring is challenging, however, since nearly half of the world's infants are not weighed at birth.

Among regions, South Asia has the highest incidence of low birth weight, with one in four newborns weighing less than 2500 grams. South Asia also has the highest rate of infants not weighed at birth, about 66 percent. Although data on 
low birth weight are adjusted to account for under-reporting, they are still likely to underestimate the true magnitude of the problem in the region [7]. In a study in Iran the prevalence of LBW was estimated 7 percent (SD 95\%), prevalence of LBW is different according to the geographical region. The prevalence in west and south is 8 percent, in south 14 percent, 7 percent in the center of Iran, 9 percent in south east and the least prevalence is in south west, north and north west [8].

\section{Materials \& Methods}

This is a descriptive analytic study and was performed on the community of children who birthed by the delivery room staff in the hospital and the health facilities of the medical universities of Iran in 2015. Demographic information was taken from the baby's mother, weight and height data measured by trained personnel both inside and outside the hospital.

Children height measured by graded CM in prone position with an accuracy of $1.0 \mathrm{~cm}$ and their weight without clothes measured also with an accuracy of 1.0 $\mathrm{cm}$ by a trained person. Data entry was carried out for 1,509,081 children and analyzed with SPSS software version 22 .

\section{Results}

Total number of births in Iran in 2015 is 1,509,081 that from this 777,351 are male, 731,014 female and 716 ambiguous (Figure 1).

The percentage of LBW neonate in male, female and ambiguous is 6.5, 7.7 and 53.9 respectively (Figure 2), also the number of LBW neonate in male, female and ambiguous was 50569, 55972 and 386 respectively. The highest percent of LBW in male was related to Sistan Blochestan province with 10.6 and the lowest percent to Lorestan province with 4.7 percent.

The highest percent of LBW in female was related to Sistan Blochestan province with 12.6 and the lowest percent to Lorestan province with 5.6 percent.

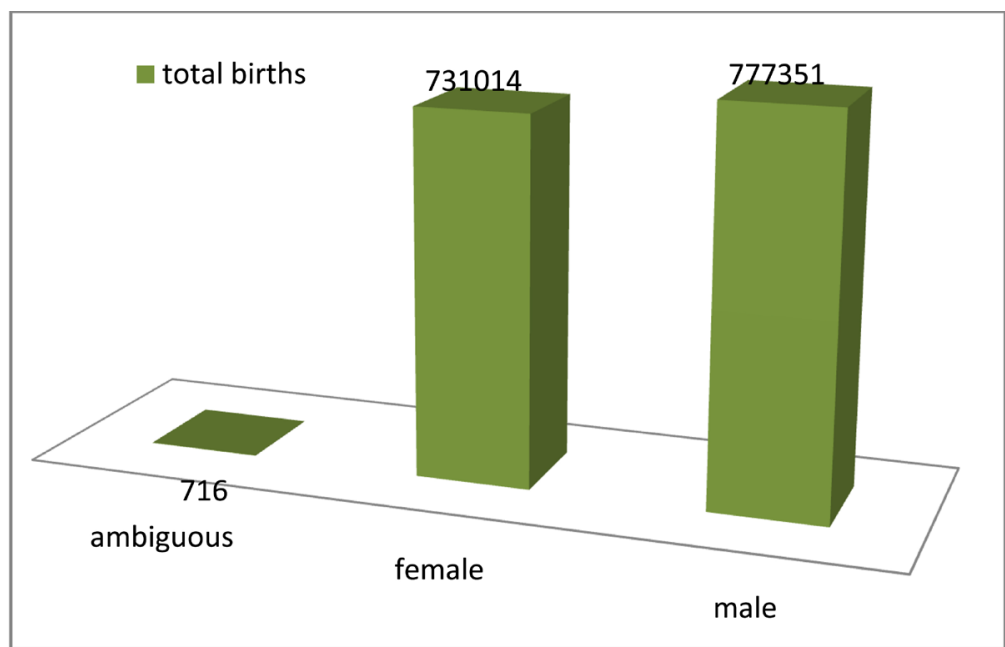

Figure 1. Total number of births according to sex. 


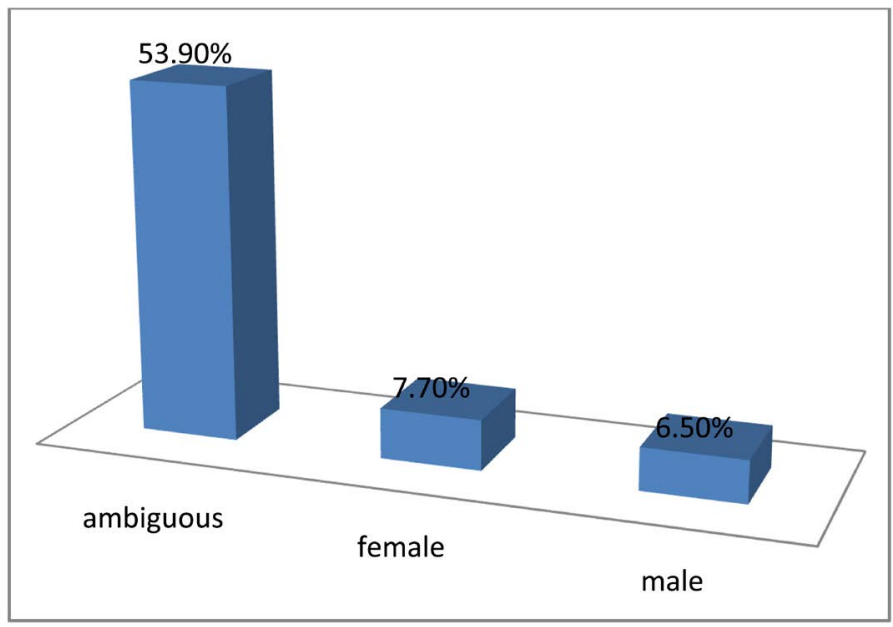

Figure 2. Percent of LBW in different sex groups.

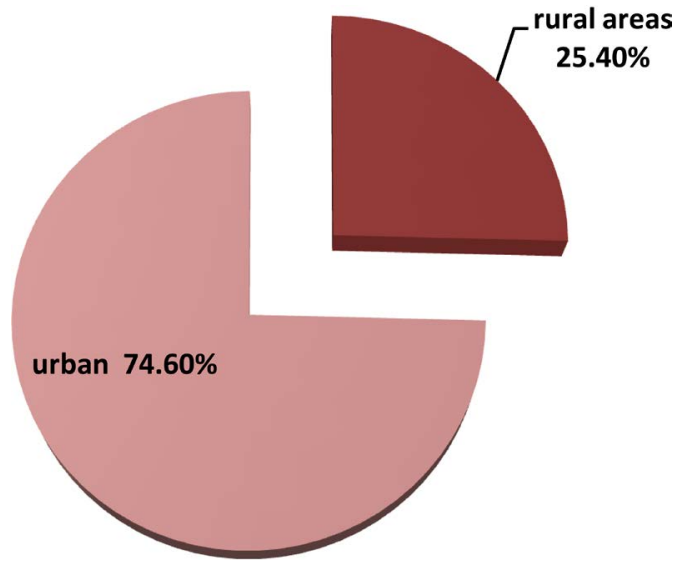

Figure 3. Percent of LBW based on rural versus urban.

25.4 percent of LBW neonates were born in rural and 74.6 percent in urban areas (Figure 3).

Percentage of LBW in single and multiple gestations is as follows:

Percent of LBW in singleton, Twin, Triplet and Quad is 6.3, 57.3, 93.4 and 95.3 respectively (Figure 4 ).

Percent of LBW according to mother's literacy level is as follows:

8.8 percent in illiterate mothers, 7.7 percent in primary school mothers, 7.3 percent in middle school mothers, 6.7 percent in high school mothers, 6.5 percent in mothers with BS and MS education and 7 percent in mothers with PHD (Figure 5).

\section{Discussion}

According to the guidelines published by World Health Organization (WHO), any neonate with a birth weight less than 2500 grams is considered to be LBW.

LBW and PTM are leading causes of adverse perinatal outcomes and are closely related to neonatal diseases and deaths. In addition, when LBW infants enter adulthood, they are more likely to suffer from hypertension, diabetes, and 


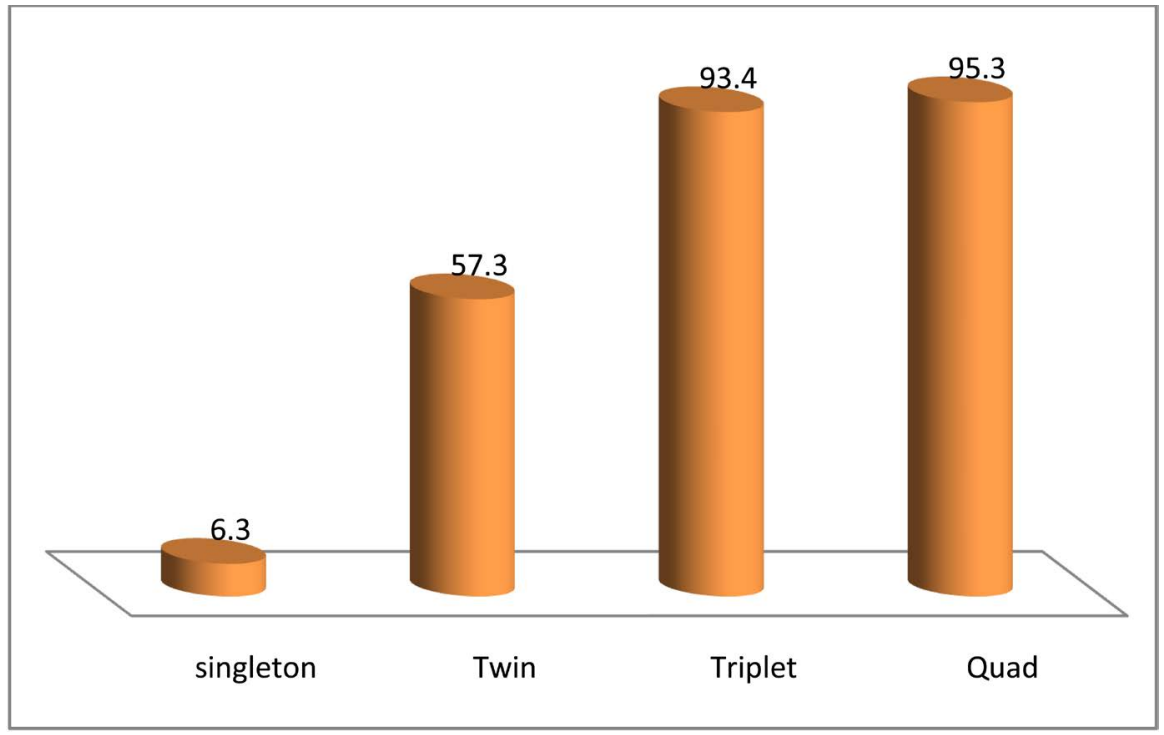

Figure 4. Percent of LBW in multi gestation.

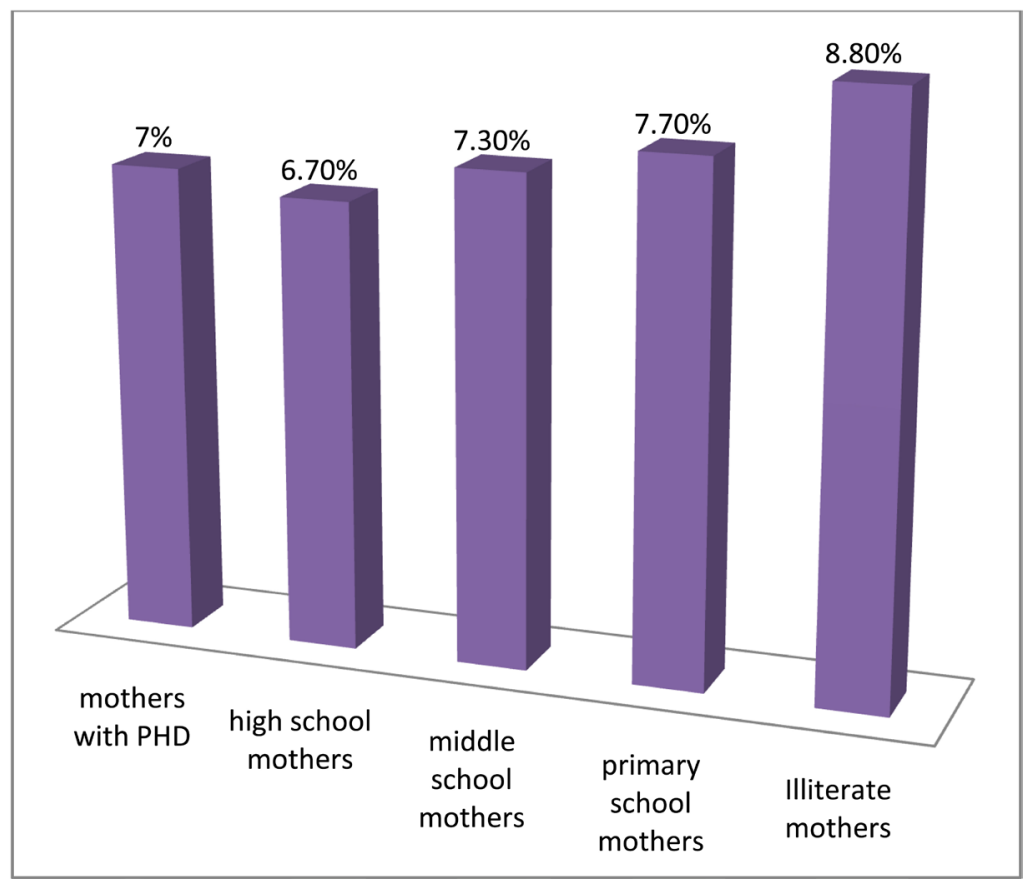

Figure 5. Percent of LBW in different literacy groups.

other metabolic diseases than individuals of normal birth weight; therefore increasing the burden on their families and the community [9] [10].

Because birth weight can be predictive of the child's health throughout life, it needs special attention. In the world, there are more than 20 million LBW infants born each year that $95.6 \%$ are born in developing countries. In 2000, the average incidence of LBW in developing countries was $16.5 \%$, which is twice as high as in developed countries [11].

Data collected during the past decade have shown that nearly half of all LBW births in the world occur in developing countries in South of Asia. The incidence 
of LBW in India is as high as $19.3 \%$ [4]. As the incidence of LBW had been increasing, in 2012, WHO proposed the goal of achieving a $30 \%$ reduction of the number of LBW infants by 2025 [12]. Similarly, the U.S. Department of Health and Human Services has made a goal of reducing the incidence of LBW to $5 \%$ [13].

In the present study, total number of births was $1,509,081$ that from this 777,351 were male, 731,014 female and 716 ambiguous. The number of LBW neonate in male, female and ambiguous was 50,569, 55,972 and 386 also the percentage of LBW births in male, female and ambiguous was 6.5, 7.7 and 53.9 respectively. The total incidence of LBW in the present study is substantially lower than that reported in India and Brazil (14.7\%) [5] [14], it was close to the incidence rate in New York State, which was 8.2\% in 2009 and the nationwide U.S. average, as reported by 246 medical centers throughout the country 2005 $(3.8 \%-10.6 \%)[3]$ [15].

Iran is a developing country; it covers a vast territory and a wide range of economic and cultural development.

Socioeconomic conditions can vary considerably in different regions, especially between north, center and southeastern coastal cities. This may be the reason why the incidence of LBW and perinatal outcomes in these regions is also different. The incidence of LBW in Southeastern of Iran is found to be the highest in the country.

Upon further analysis, the incidence of LBW in Iran is found to be similar to that in developed countries. LBW is caused by both direct factors such as pregnancy complications and by indirect factors such as socio-economic development (condition). The factors that contribute to LBW differ across different countries and also different regions within certain countries.

The highest percentage of LBW in male and female was related to Sistan Blochestan province with 10.6 and 12.6 respectively. Sistan Blochestan is located in Southeastern of Iran and is one of the most deprived provinces in the country.

25.4 percent of the LBW neonates are born in the rural areas and 74.6 percent in urban areas. This shows that higher level of the life condition can have vice verse effect on LBW.

The percentage of LBW is reduced with increasing mother's literacy in the present study except mothers with PHD education.

By increasing the number of multiple pregnancies, the number and percent of LBW is increased. The percentage of LBW according to the number of pregnancies is as follows:

6.3 percent in singeleton, $57.3 \%$ in twins, $93.4 \%$ in triplet, $95.3 \%$ in Quad and $100 \%$ in the more gestation.

Regarding the prognosis of LBW, with development of perinatology, the survival rate of LBW infants has substantially increased. However, some adverse outcomes are still relatively common, especially long-term complications such as cerebral palsy, delayed neurodevelopment and visual and hearing impairments. These all have adverse effects on adults and their offspring. For these reasons, 
LBW merits considerable attention. To reduce the incidence of LBW, increases in nutrient intake before conception, proper pregnancy education and good health care during pregnancy should be fostered and high-risk factors for LBW should be avoided.

This may allow LBW to be prevented or at least diagnosed early and treated properly. In addition, comprehensive assessment of the mother and child situation should be made to allow the selection of a proper delivery method, thus improving the prognosis of LBW neonates.

\section{Conclusion}

The incidence of LBW in Iran is higher in deprived provinces such as Sistan Blochestan in southeast of Iran. The incidence of LBW is highly related to the maternal level of education. This shows that by increasing mothers' literacy and also their training about pregnancy and maternal care, the incidence of LBW babies decreases. The incidence of LBW in rural and urban is the same according to the population density; this shows that the quality of health delivery in the rural area is not low. Reducing the incidence of LBW is essential for improving quality of life in developing countries like Iran.

\section{References}

[1] World Health Organization (1992) International Statistical Classification of Diseases and Related Health Problems Tenth Revision. World Health Organization, Geneva.

[2] Kramer, M.S. (1987) Determinants of Low Birth Weight: Methodological Assessment and Meta-Analysis. Bulletin of the World Health Organization, 65, 663-737.

[3] de Bernabé, J.V., Soriano, T., Albaladejo, R., Juarranz, M., Calle, M.E., Martínez, D. and Dominguez-Rojas, V. (2004) Risk Factors for Low Birth Weight: A Review. European Journal of Obstetrics \& Gynecology and Reproductive Biology, 116, 3-15. https://doi.org/10.1016/j.ejogrb.2004.03.007

[4] Sachdev, H.P.S. (2001) Low Birth Weight in South Asia. International Journal of Diabetes in Developing Countries, 21, 1.

[5] Bharati, P., Pal, M., Bandyopadhyay, M., Bhakta, A., Chakraborty, S. and Bharati, P. (2011) Prevalence and Causes of Low Birth Weight in India. Malaysian Journal of Nutrition, 17, 301-313.

[6] World Health Organization (1992) Low Birth Weight: A Tabulation of Available Information, WHO/MCH/92.2. World Health Organization, Geneva, and UNICEF, New York, 2.

[7] UNICEF and WHO (2004) Low Birth Weight: Country, Regional and Global Estimates. UNICEF, New York, 1.

[8] Nazari, F., et al. (2013) Prevalence \& Trends of LBW in Iran: A Systematic Review and Meta Analysis Study. Journal of Shahid Beheshti University of Medical Sciences School of Nursing, 22, 45-52.

[9] Chen, W., Srinivasan, S.R., Yao, L., Li, S., Dasmahapatra, P., Fernandez, C., et al. (2012) Low Birth Weight Is Associated with Higher Blood Pressure Variability from Childhood to Young Adulthood: The Bogalusa Heart Study. American Journal of Epidemiology, 176, S99-S105. https://doi.org/10.1093/aje/kws298 
[10] Christensen, D.L., Kapur, A. and Bygbjerg, I.C. (2011) Physiological Adaption to Maternal Malaria and Other Adverse Exposure: Low Birth Weight, Functional Capacity, and Possible Metabolic Disease in Adult Life. International Journal of $G y$ necology \& Obstetrics, 115, S16-S19.

https://doi.org/10.1016/S0020-7292(11)60006-4

[11] World Health Organization (2006) Neonatal and Perinatal Mortality. Country, Regional and Global Estimates. World Health Organization, Geneva.

[12] World Health Organization (2012) Global Targets to Improve Maternal, Infant and Young Child Nutrition, Policy Brief.

http://www.who.int/nutrition/global-target-2025/en/

[13] New York State Department of Health (2011) New York State Department of Health: Table 11: Low Birth weight Live Births (2500 grams) by Mother's Age and Resident County New York State-2009.

https://www.health.ny.gov/statistics/vital statistics/2009/table11.htm

[14] Coutinho, P.P., Cecatti, J.G., Surita, F.G., Souza, J.P. and Morais, S.S. (2009) Factors Associated with Low Birth Weight in a Historical Series of Deliveries in Campinas, Brazil. Revista Da Associacao Medica Brasileira, 55, 692-699.

https://doi.org/10.1590/S0104-42302009000600013

[15] Thompson, L.A., Goodman, D.C., Chang, C.H. and Stukel, T.A. (2005) Regional Variation in Rates of Low Birth Weight. Pediatrics, 116, 1115-1116.

https://doi.org/10.1542/peds.2004-1627 